08

\title{
Топография поверхности и пропускание света кварцевыми окнами после экспозиции в высокочастотном разряде в дейтерии и смеси дейтерия с азотом
}

\author{
(C) А.Е. Городецкий, ${ }^{1}$ А.В. Маркин, ${ }^{1}$ В.Л. Буховец, ${ }^{1}$ В.И. Золотаревский, ${ }^{1}$ Р.Х. Залавутдинов, ${ }^{1}$ Н.А. Бабинов, ${ }^{2}$ \\ А.М. Дмитриев, ${ }^{2}$ А.Г. Раздобарин, ${ }^{2}$ Е.Е. Мухин ${ }^{2}$
}

${ }^{1}$ Институт фризической химии и электрохимии РАН, 119071 Москва, Россия

${ }^{2}$ Физико-технический институт им. А.И. Иоффре РАН, 194021 Санкт-Петербург, Россия

e-mail: aegorodetsky@mail.ru

Поступило в Редакцию 25 мая 2020 г.

В окончательной редакции 24 июля 2020 г.

Принята к публикации 11 августа 2020 г.

Исследовано влияние высокочастотного разряда на изменение топографии поверхности оптического кварца КУ-1 и пропускание видимого света $(400-1000 \mathrm{~nm})$. Рабочими газами разряда являлись $\mathrm{D}_{2}$ и смесь $\mathrm{D}_{2} / \mathrm{N}_{2}$, в которой доля $\mathrm{N}_{2}$ составляла $25 \mathrm{~mol} \%$. Добавление азота увеличивало скорость распыления с 60 до $300 \mathrm{~nm} / \mathrm{h}$ при сохранении стехиометрии поверхностных слоев. После экспозиции в плазме среднеквадратичная шероховатость поверхности уменьшалась с 1.3 до $0.6 \mathrm{~nm}$. Прозрачность кварца не изменилась. Анализ шероховатости и расчет диффузного рассеяния света с длиной волны $400 \mathrm{~nm}$, прошедшего сквозь кварц, выполнены с использованием функций спектральной плотности мощности.

Ключевые слова: кварц КУ-1, высокочастотный разряд, дейтерий, азот, атомно-силовая микроскопия, PSDфункция, пропускание света.

DOI: $10.21883 / J T F .2021 .02 .50366 .180-20$

\section{Введение}

При выборе материала первого окна, защищающего внутривакуумные компоненты диагностики томсоновского рассеяния (ДТР) и лазерно-индуцированной флуоресценции (ЛИФ) в диверторе ИТЭР (International Thermonuclear Experimental Reactor или Международный экспериментальный термоядерный реактор), следует учитывать возможную модификацию оптических характеристик окна в условиях дивертора токамакареактора. В первую очередь потоки нейтронов и гаммаквантов, проникающих в область расположения оптики в диагностическом канале, могут привести к значительному уменьшению коэффициента пропускания окна. В работе [1] было показано, что одним из наиболее радиационно-стойких материалов, сохраняющих свою прозрачность при указанных радиационных воздействиях, является плавленый кварц КУ-1 (далее КУ). Помимо этого обращенное к плазме защитное окно будет подвержено осаждению продуктов эрозии первой стенки, что может привести к ухудшению его прозрачности для зондирующего лазерного излучения в широком спектральном диапазоне (табл. 1). В табл. 1 длины волн в атомных спектрах элементов обозначены как BeII, HeI, HеII и т.д.

В этой связи возникает задача восстановления пропускания материала окна путем очистки его поверхности от металлических осадков (Ве и $\mathrm{W})$ в плазме газового разряда. В связи с высокой чувствительностью коэффициента пропускания окна к осаждению металлических пленок толщиной в несколько единиц нанометров предлагается проводить очистку поверхности окна непосредственно во время рабочего импульса, когда основными компонентами нейтрального газа будут изотопы водорода, гелий а также азот. Азот, аргон или неон вводят для увеличения радиационных потерь и, следовательно, распределения выделяемой в диверторе мощности на большую площадь первой стенки [2].

Ранее, до замены графитовых пластин дивертора ИТЭР на вольфрамовые, роль излучателя выполнял эродированный углерод. В таком случае в качестве одного из вариантов рабочего газа чистящего разряда естественно испытать смесь изотопов водорода с азотом.

В наших экспериментах добавление азота в дейтериевую плазму чистящего разряда увеличивало скорость распыления металлических осадков (Al, Мо и Ве) [3]. Предложенная методика была апробирована в экспери-

Таблица 1. Длины волн $[\mathrm{nm}]$ лазерного излучения ДТР и ЛИФ в диверторе ИТЭР

\begin{tabular}{|c|c|c|c|c|c|c|c|c|}
\hline \multicolumn{9}{|c|}{ Диагностическая система } \\
\hline \multicolumn{3}{|c|}{ ДТР } & $\begin{array}{l}\text { ЛИФ } \\
\text { (Bell) }\end{array}$ & \multicolumn{3}{|c|}{ ЛИФ (HeI) } & $\begin{array}{c}\text { ЛИФ } \\
\text { (Hell) }\end{array}$ & $\begin{array}{c}\text { ЛИФ } \\
(\mathrm{H}, \mathrm{D}, \mathrm{T})\end{array}$ \\
\hline 946 & 1047 & 1064 & 436.1 & 388.9 & 501.6 & 667.8 & 1012 & 1875 \\
\hline
\end{tabular}


ментах по удалению Al (модельного материала, аналога Ве) с поверхности плавленого кварца КУ в скрещенных разрядах постоянного тока и высокочастотном емкостном разряде (далее ВЧ-разряд) в смеси $\mathrm{D}_{2} / \mathrm{N}_{2}$. Поверхность кварца полностью очищалась от нанесенной пленки $\mathrm{Al}$ толщиной $30 \mathrm{~nm}$ за $30 \mathrm{~min}$ экспозиции в плазме разряда в смеси $\mathrm{D}_{2} / \mathrm{N}_{2}$, где доля $\mathrm{N}_{2}$ составляла $25 \mathrm{~mol} \%$ (далее $\mathrm{D}_{2} / \mathrm{N}_{2}$ ). Одна из проблем, возникающая в методике плазменной чистки, связана с необходимостью многократного повторения процесса до восстановления исходных оптических параметров КУ. Молекулярный азот обычно химически инертен, но его радикалы и ионы, а также образующийся в плазме аммиак реакционноспособны в отношении многих материалов [3] и, возможно, к КУ [4,5].

Цель настоящей работы - исследование изменений топографической структуры поверхности и оптической стойкости кварца КУ (коэффициента пропускания света в диапазоне длин волн 400-1000 nm) после экспозиции в чистящих разрядах $\mathrm{D}_{2}$ или в смеси $\mathrm{D}_{2} / \mathrm{N}_{2}$.

\section{1. Методика эксперимента}

Эксперименты проводили в лабораторной установке, представленной на рис. 1. ВЧ-генератор 10 с рабочей частотой $13.56 \mathrm{MHz}$ (RF-3, RF VII, Inc) создавал разряд между нагруженным электродом 11 площадью $1 \mathrm{~cm}^{2}$ и заземленным электродом 12 площадью $10 \mathrm{~cm}^{2}$. Материал электродов - молибден. На электроде 11 помещали образец КУ размером $1 \times 1 \times 0.2 \mathrm{~cm}$. При падающей мощности $50 \mathrm{~W}$ и отраженной мощности 3-5 W на поверхности образца относительно плазмы создавалось автосмещение - $300 \mathrm{~V}$. Разряд постоянного тока величиной $30 \mathrm{~mA}$ зажигали в кварцевой трубке внутреннего диаметра $1.9 \mathrm{~cm}$ между полым катодом 8 и заземленным анодом 9, изготовленными из нержавеющей стали и расположенными на расстоянии $65 \mathrm{~cm}$ один от другого. Электроды ВЧ-разряда находились на расстоянии $19 \mathrm{~cm}$ от анода. Разряд постоянного тока играл вспомогательную роль: за $15 \mathrm{~min}$ до включения ВЧ-разряда его включали для очистки стенки разрядной трубки от адсорбированных газов. В дальнейшем он облегчал зажигание и устойчивое горение ВЧ-разряда. Массовые расходы $\mathrm{D}_{2}$ и $\mathrm{N}_{2}$ задавали блоком регуляторов расхода 1 газа с точностью $0.1 \mathrm{ml} / \mathrm{min}$ at standard conditions (s.c.), которые составляли $14 \mathrm{ml}$ (s.c.) $/ \mathrm{min}$ в чистом $\mathrm{D}_{2}$ и в смеси $\mathrm{D}_{2} / \mathrm{N}_{2}-8.1$ и $2.7 \mathrm{ml}$ (s.c.) $/ \mathrm{min}$ соответственно. Доля $\mathrm{N}_{2}$ в потоке смеси была равна $25 \mathrm{~mol} \%$. Давление нейтрального газа измерялось емкостным преобразователем. Во всех опытах давление поддерживалось равным 15 Ра дросселирующим вентилем, установленным перед форвакуумным насосом 2. Температура образца не превышала $100^{\circ} \mathrm{C}$.

Определение скорости распыления кварца КУ $[\mathrm{nm} / \mathrm{s}]$ осуществляли методом взвешивания образцов (с точностью $0.5 \mu \mathrm{g})$ до и после экспозиции в плазме.

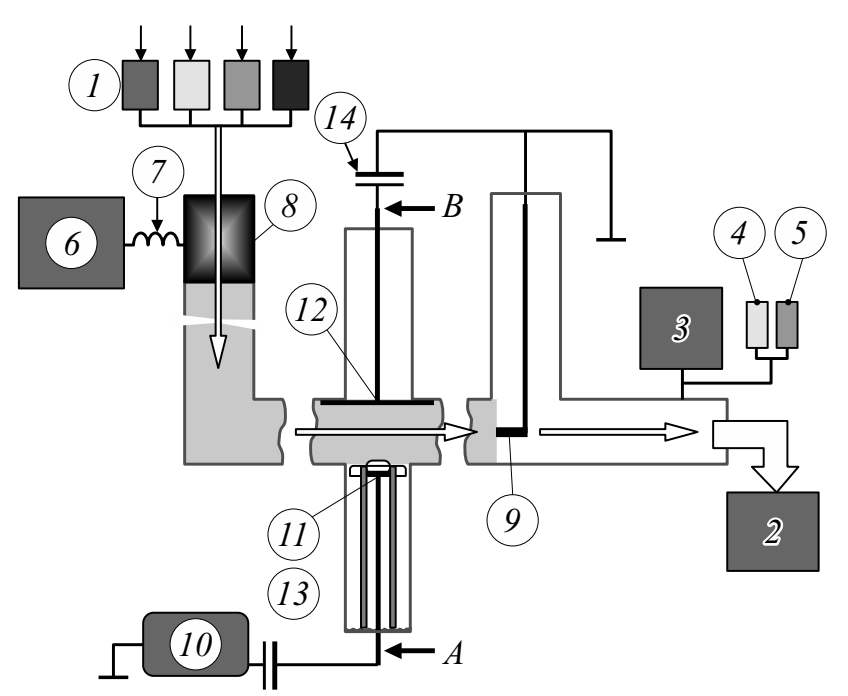

Рис. 1. Принципиальная схема установки: 1 - блок регуляторов расхода газа, 2 - форвакуумный насос, 3 - квадрупольный масс-спектрометр, 4 - абсолютный емкостной манометр, 5 - манометр Пирани, 6 - высоковольтный источник постоянного тока, 7 - дроссель, $8-$ полый катод, 9 - анод, 10 - ВЧ-генератор, 11 - высоковольтный ВЧэлектрод с образцом, 12 - заземленный по ВЧ-электрод, 13 и 14 - разделительные конденсаторы, $A$ и $B$ - точки подключения осциллографа. Фигурными стрелками показано направление потока газа.

Измерение коэффициента пропускания света производили с помощью стенда, собранного с использованием оптоволоконных компонент производства AVANTES (www.avantes.com). Источником света служила галогеновая лампа со стабилизацией мощности (AvaLight$\mathrm{HAL}$ ). Пучок света круглого сечения диаметром $3 \mathrm{~mm}$, формируемый коллимационной линзой (COL-UV/VIS), проходил через анализируемую кварцевую пластину и поступал внутрь интегрирующей сферы (AvaSphere50). Внутренняя поверхность сферы покрыта диффузно отражающим слоем порошкового фторопласта. Полный коэффициент отражения такого покрытия в диапазоне длин волн света от 400 до $1100 \mathrm{~nm}$ превышает 98\%. После многократного рассеяния внутри сферы свет попадал на вход оптоволоконного кабеля, закрепленного на одном из отверстий сферы и соединенного с оптическим спектрометром AvaSpec-2048-USB2. Коэффициент пропускания $T$ кварца рассчитывали как отношение спектра образца к спектру, измеренному в его отсутствии.

Рельеф и шероховатость поверхности кварцевых пластин анализировали с помощью атомно-силового микроскопа (ACM) „Enviroscope“ (Bruker) в полуконтактном режиме на частоте $330 \mathrm{kHz}$ с кремниевым кантилевером радиусом $10 \mathrm{~nm}$, изготовленным фирмой TipsNano (филиал в г. Зеленоград). Исследование топографии проводили в различных областях образцов на площадях 1, 25 и $100 \mu \mathrm{m}^{2}$. Цифровую обработку изображений на площадях $10 \times 10 \mu \mathrm{m}$ осуществляли в интервале простран- 

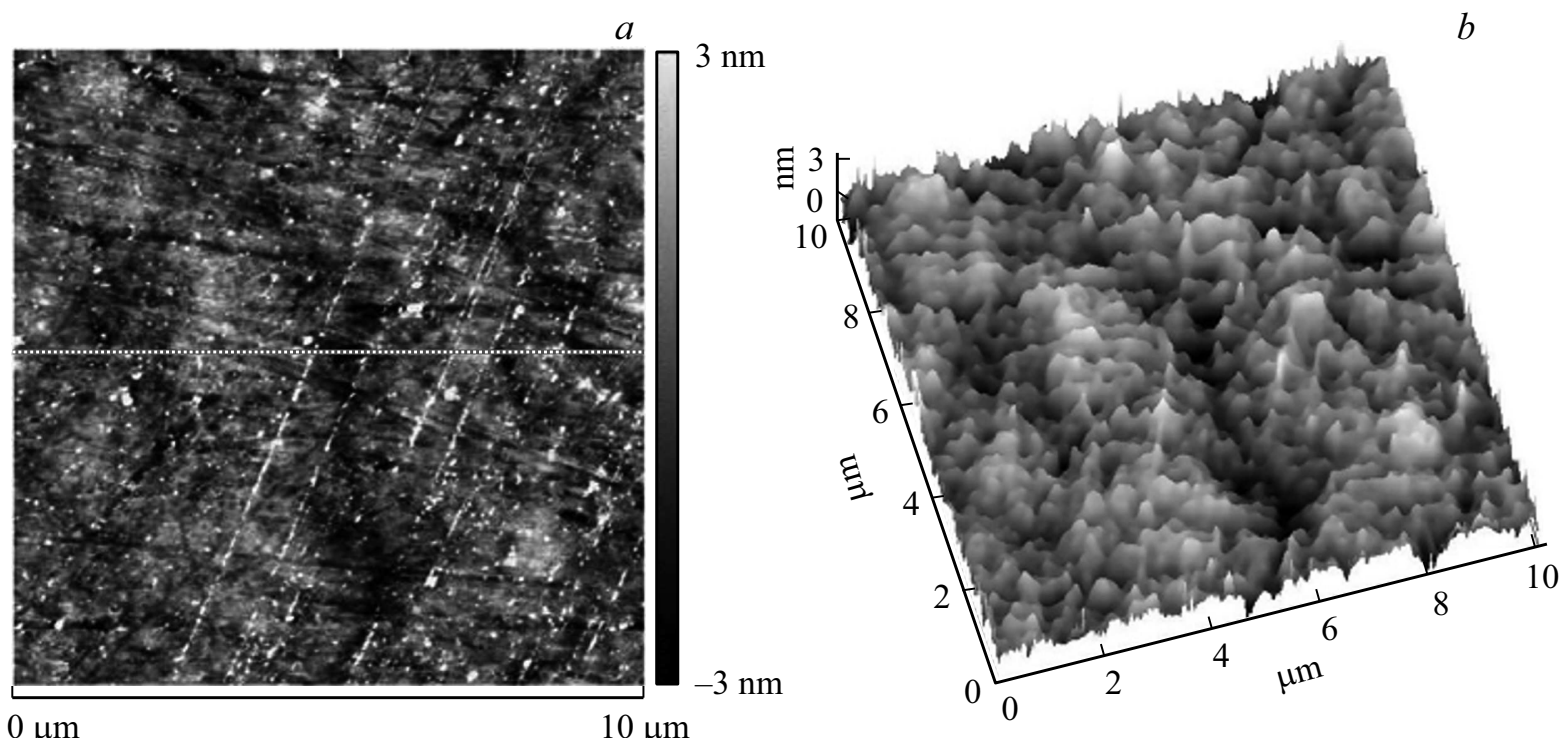

Рис. 2. Топография исходной поверхности кварца КУ, $R_{q}=1.3 \mathrm{~nm}(a)$; диметрическая проекция рельефа поверхности: $S_{g}=100 \mu \mathrm{m}^{2} ; S_{\mathrm{ph}}=100.1 \mu \mathrm{m}^{2} ;\left(S_{\mathrm{ph}}-S_{g}\right) / S_{g}=0.001(b)$.

ственных частот $0.1-25 \mu \mathrm{m}^{-1}$ по программе Nanoscope Analysis фирмы Bruker. Волнистость поверхности кварца в субмиллиметровом масштабе корректировали с помощью программного фильтра. Многократный анализ изображений, построение вертикальных, горизонтальных и изотропных PSD-функций позволил заключить, что топографические характеристики поверхности не зависят от координат исследуемой локальной площади и ее ориентации, т.е. поверхность образца кварца изотропна и однородна.

Химическое окружение атомов кремния в оксиде определяли с помощью рентгеновской фотоэлектронной спектроскопии (РФЭС) с зондирующим излучением $\operatorname{Mg} K \alpha$, энергия фотонов $E=1253.6 \mathrm{eV}$.

\section{2. Топография поверхности и спектры пропускания исходных пластин кварца КУ-1}

Основными дефектами исходной поверхности кварца, видимыми в оптическом микроскопе, были полировочные царапины с боковым выносом материала в виде бортиков или навалов. Появление царапин вызвано пластическим деформированием поверхности заостренной полирующей частицей при нагрузке на частицу, превышающей предел текучести КУ (50 МРа). Иногда на царапинах можно было видеть поперечные выемки, связанные с хрупким разрушением материала при нагрузках на абразив, превышающих предел прочности КУ, связанным с модулем сдвига $-31 \mathrm{GPa}$.

Царапины и следы хрупкого выкрашивания были хорошо видны и в АСМ (рис. 2,a). Ансамбль выступов и впадин, показанный на диметрической поверхности

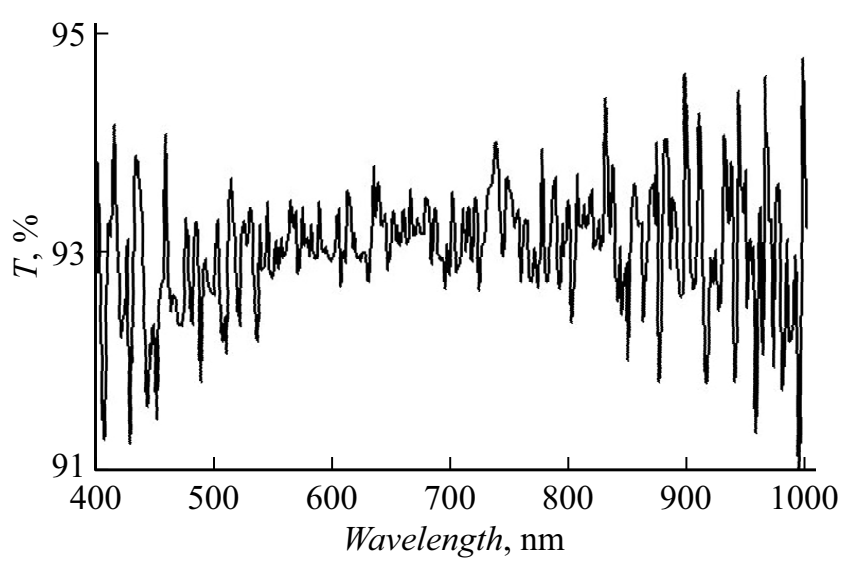

Рис. 3. СП света сквозь исходную пластину кварца.

(рис. 2,b), - результат пластического выглаживания при финишной полировке. Реальное соотношение между геометрической проекцией $\left(S_{g}\right)$ и физическим размером площади $\left(S_{\mathrm{ph}}\right)$ очень небольшое: $\left(S_{\mathrm{ph}}-S_{g}\right) / S_{g}=0.001$.

Из анализа контраста изображения можно заключить, что глубина темных впадин и высота светлых возвышений вокруг впадин составляли 1.5-2 nm. Отдельные белые точки субмикронного размера и высотой в $1-3 \mathrm{~nm}$, вероятно, сформировались в результате хрупкого выкрашивания частиц кварца и последующего прилипания к чистой поверхности при финишной полировке.

Согласно измерениям, в АСМ среднеквадратичная шероховатость полированной поверхности кварца $R_{q}=1.25 \mathrm{~nm}$, что свидетельствует об оптически совершенной поверхности кварцевого окна.

Типичный спектр пропускания (СП) света исходного кварца представлен на рис. 3. В диапазоне 400-1000 nm 


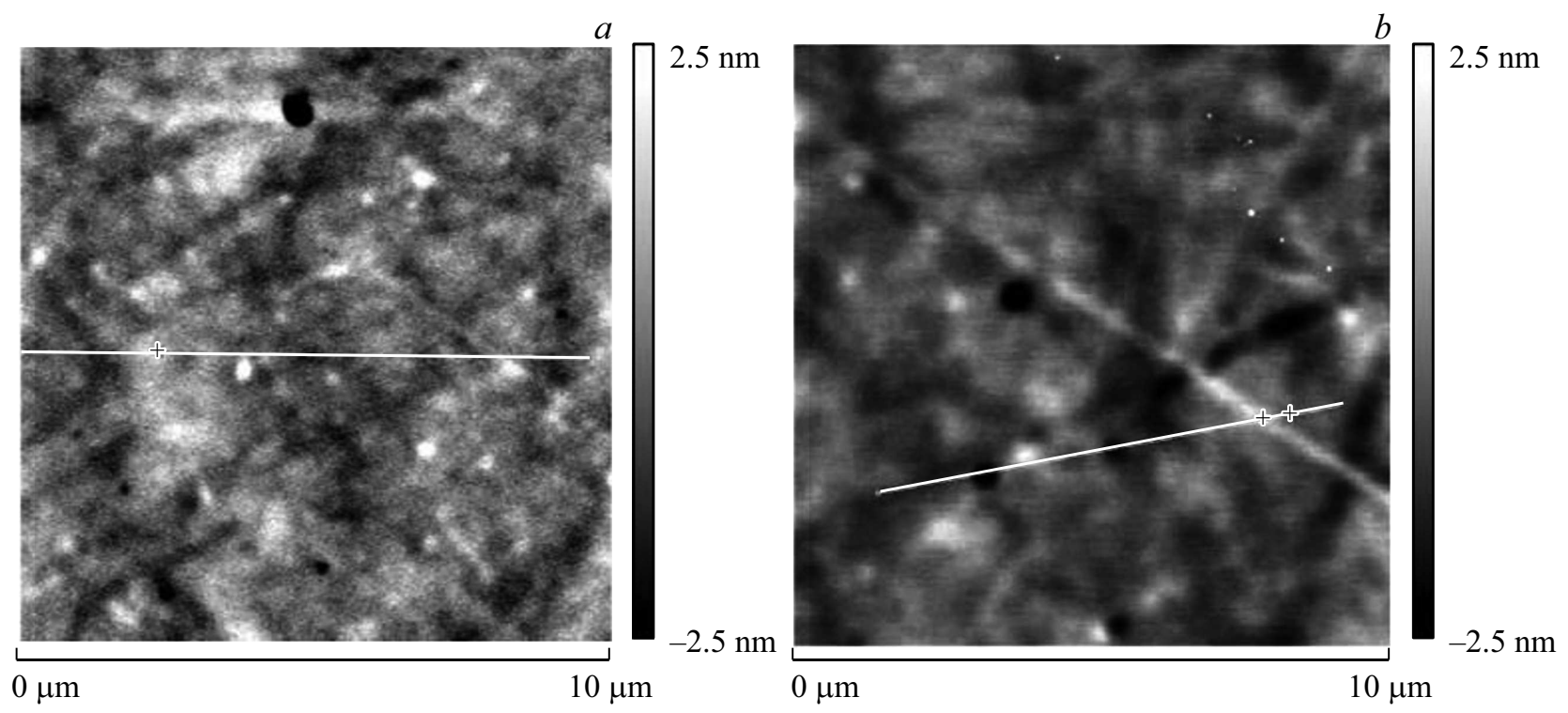

Рис. 4. Топография поверхности пластин КУ после экспозиции в течение $4 \mathrm{~h}$ в плазме в дейтерии, $R_{q}=(0.85 \pm 0.03) \mathrm{nm}$; $\left(S_{\mathrm{ph}}-S_{g}\right) / S_{g}=0.00024(a)$ и в смеси $\mathrm{D}_{2} / \mathrm{N}_{2}, R_{q}=(0.63 \pm 0.02) \mathrm{nm} ;\left(S_{\mathrm{ph}}-S_{g}\right) / S_{g}=0.00002(b)$.

коэффициент пропускания $T$, рассчитанный по формуле $T=2 n /\left(n^{2}+1\right)$, составлял 93\% для показателя преломления $n=1.46$. Формула верна при учете многократных отражений на входной и выходной гранях пластины и отсутствии поглощения.

\section{3. Экспозиция пластин кварца в разряде $D_{2}$ и смеси $D_{2} / N_{2}$}

В результате экспозиции в плазме дейтерия в течение $4 \mathrm{~h}$ убыль массы составила $(44 \pm 4) \mu \mathrm{g}$ при площади облученной поверхности $0.81 \mathrm{~cm}^{2}$. С учетом плотности кварца $\left(2.2 \mathrm{~g} / \mathrm{cm}^{3}\right)$ толщина распыленного слоя кварца оказалась равной $(247 \pm 22) \mathrm{nm}$, а скорость распыления - $61 \mathrm{~nm} / \mathrm{h}$.

После облучения в плазме $\mathrm{D}_{2}$ или в $\mathrm{D}_{2} / \mathrm{N}_{2}$ спектры пропускания в пределах фона совпадали со спектрами исходных образцов до облучения (рис. 3). Следует отметить, что относительно высокий фон при измерениях был обусловлен маломощным источником света, что при использовании интегрирующей сферы приводило к длительной экспозиции детектора (не менее $1 \mathrm{~s}$ ). Все это не позволяло накапливать более 5 спектров для усреднения.

На топографической картинке рис. 4, а видно, что вновь сформированная поверхность состоит из выступов, напоминающих облака, с узкими углублениями между ними. В облаках просматриваются кластерные скопления субмикронного масштаба. По данным АСМ шероховатость на представленном изображении составила $R_{q}=0.85 \mathrm{~nm}$ (рис. 4,a). Максимальный перепад расстояний между впадинами и выступами не превышал
4-5 nm. В целом ионное распыление сопровождалось выглаживанием поверхности.

По данным РФЭС в спектре основного уровня $\mathrm{Si} 2 p$ от поверхностного слоя облученного кварца присутствовал только пик кремния с максимальной степенью окисления $\mathrm{SiO}_{2}$, т.е. дейтериевая плазма не восстанавливала оксид кремния. Метод РФЭС по химическому сдвигу пика Si 2p3/2 позволял обнаружить присутствие долей монослоя $(<0.5 \mathrm{~nm})$ окиси кремния $(\mathrm{SiO})$ или полностью восстановленного кремния $(\mathrm{Si})$. Правда, все измерения РФЭС были выполнены ex-situ.

При экспозиции в плазме в смеси $\mathrm{D}_{2} / \mathrm{N}_{2}$ за $4 \mathrm{~h}$ был удален слой кварца толщиной $1200 \mathrm{~nm}$ (скорость распыления $300 \mathrm{~nm} / \mathrm{h}$ ). В спектрах РФЭС после плазмы $\mathrm{D}_{2} / \mathrm{N}_{2}$ и $\mathrm{H}_{2} / \mathrm{N}_{2}$ в приповерхностном слое кварца регистрировали пики азота. Одно из объяснений повышенной скорости распыления - образование на поверхности $\mathrm{SiO}_{2}-\mathrm{ND}_{3}$-комплексов, слабо связанных с кварцем [4,5]. В работе [6] такую повышенную эрозию назвали химически стимулированным физическим распылением, в отличие от распыления (например, галогенами) с образованием летучих радикалов. В отличие от образца, экспонированного в $\mathrm{D}_{2}$-плазме, в этом опыте дискретная структура облаков не просматривалась. На вновь образованной поверхности (рис. 4,b) шероховатость уменьшилась до значений $R_{q}=0.57 \mathrm{~nm}$. Однако следы от царапин еще были видны. Кроме размытых следов от царапин встречались углубления диаметром до $2 \mu \mathrm{m}$ и глубиной до $10 \mathrm{~nm}$. Размытые следы полировки можно увидеть и на рис. $3, a$.

Согласно проведенным нами расчетам, при появлении пленки кремния толщиной $1 \mathrm{~nm}$ или моноокиси кремния $(\mathrm{SiO})$ толщиной 5-10 nm коэффициент пропускания T в коротковолновой области должен был уменьшиться 

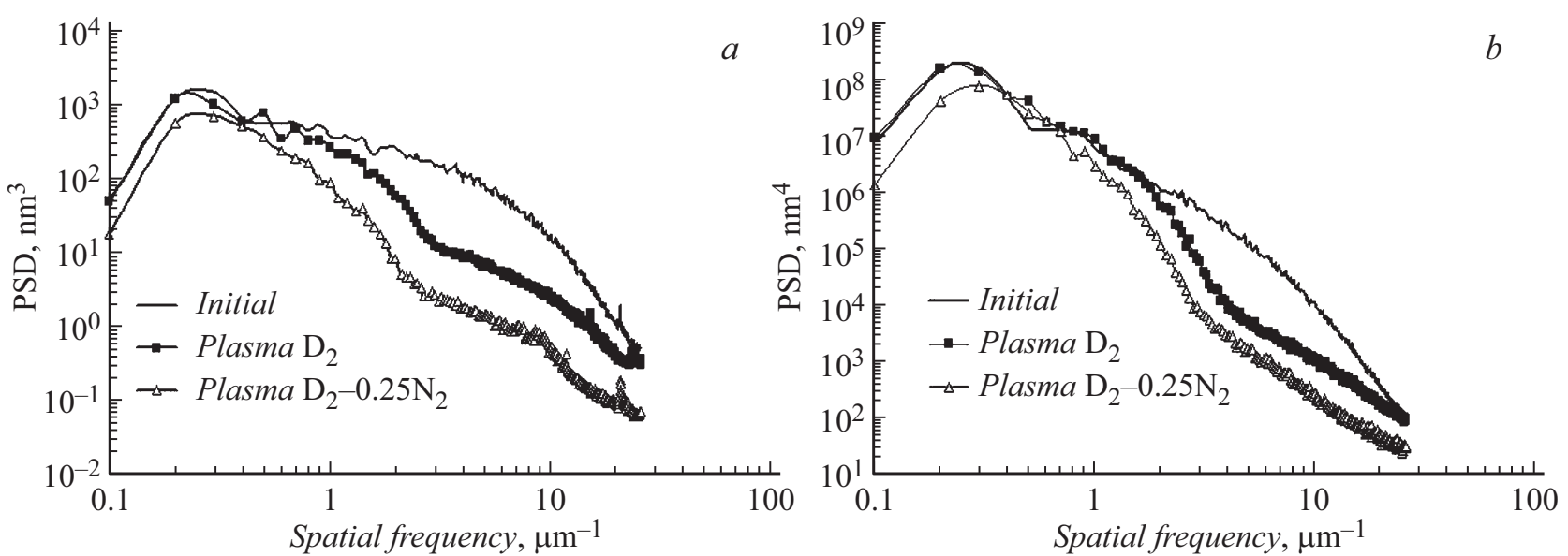

Рис. 5. Одномерные $(a)$ и двумерные $(b)$ PSD-функции исходной поверхности КУ и поверхности после экспозиции в плазме $\mathrm{D}_{2}$ и $\mathrm{D}_{2} / \mathrm{N}_{2}$ в течение $4 \mathrm{~h}$.

на 2-3\%. По данным СП в последнем опыте, как и в случае $\mathrm{D}_{2}$-плазмы, коэффициенты $T$ после экспозиции не изменились. Процесс восстановления оксида кремния до субоксидов или до кремния не обнаружен. СП исходного кварца и кварца, экспонированного в плазме смеси $\mathrm{D}_{2} / \mathrm{N}_{2}$, совпадали (рис. 3 ).

\section{4. Анализ топографии поверхности с помощью функции спектральной плотности мощности (PSD-функции)}

Сканирование неровностей поверхности в АCM по линии или по площади позволяет построить одномерные $1 D$ - и двухмерные 2D-PSD-функции (Power Spectral Density function). Одномерная PSD-функция с размерностью $\left[\mathrm{m}^{3}\right]$ является фурье-преобразованием статистического распределения неровностей поверхности в спектр пространственных синусоидальных частот $f$ с определенной амплитудой для каждой частоты (рис. 5,a). В результате рельеф поверхности представляется как суперпозиция синусоид различной частоты с размерностью $\left[\mathrm{m}^{-1}\right]$. PSD-функция показывает, какой вклад вносит конкретная частота $f$ в эффективную среднеквадратичную шероховатость $\sigma$ (root-mean-square, rms) с размерностью $[\mathrm{nm}]$. Величины $\sigma$ вычисленные из построенных PSD-функций, могут отличаться от значений $R_{q}$, определенным непосредственно по топографическим изображениям.

Интеграл от PSD-функции в выбранной области частот $\left(f_{1}-f_{2}\right)$ определяет квадрат эффективной среднеквадратичной шероховатости $\sigma^{2}$, отвечающий выделенному интервалу частот. Это дает возможность анализировать вклады различных интервалов частот в суммарную шероховатость всей исследуемой пластины.

В области сравнительно высоких частот PSD-функция изотропной само-подобной поверхности уменьшается как $f^{-\beta}$. Показатель степени $\beta$ связан с экспонентой
Херста (Hurst exponent, $H$ ). В случае одномерной PSDфункции $H=(\beta-1) / 2$ [7]. В свою очередь $H$ связан с фрактальным размером шероховатой поверхности. Для так называемой броуновской поверхности с гауссиановским распределением дефектов $\beta=2$ и $H=0.5$. Примеры построения одномерной PSD-функции для шероховатой поверхности с дефектами различного типа приведены в [8]. Анализ сверхгладких кварцевых поверхностей с помощью PSD-функций приведен в $[9,10]$.

Построение PSD-функций с помощью программы, прилагаемой к АСМ, для нескольких горизонтальных и вертикальных линейных проходов позволило считать, что одномерная, монотонно убывающая с увеличением $f$ функция $\operatorname{PSD}(f)$ достаточно полно отражает особенности рельефа поверхности кварцевых пластин. Для каждой PSD-функции, построенной на основании измерения амплитуд шероховатости на длине $L=10 \mu \mathrm{m}$ с использованием $N$ точек, пространственная частота $f$ изменяется от $1 / L$ до $N / 2 L$. В нашем случае $N=512$ и $f_{\text {min }}=0.1 \mu \mathrm{m}^{-1}$, a $f_{\text {max }}=25.6 \mu \mathrm{m}^{-1}$ (рис. 5, a). Для анализа топографических изменений поверхности авторы использовали $1 D$ PSD-функции (рис. 5,a), а для исследования светорассеяния $2 D$ PSD-функции, построенные из АСМ измерений (рис. $5, b$ ).

Пониженное значение $1 D$ PSD-функций от трех исследованных образцов кварца при частоте $1 / L=0.1 \mu \mathrm{m}^{-1}$, возможно, является артефактом, связанным с ограничением длинноволновой части фурье-преобразования. Появление узких пиков вблизи верхней границы спектра может быть вызвано как эффектами упорядочения отдельных видов поверхностных дефектов, так и артефактами, связанными с подготовкой поверхности образца к просмотру в АСМ и программными неточностями при фурье-преобразованиях [11].

Если условно разделить весь диапазон пространственных частот на три интервала $\Delta f$ : низких $\left(0.2-1 \mu \mathrm{m}^{-1}\right)$, средних $\left(1-3 \mu \mathrm{m}^{-1}\right)$ и высоких $\left(3-25.6 \mu \mathrm{m}^{-1}\right)$ частот, то можно видеть, что после экспозиции в плазме в 
Таблица 2. Квадраты эффективной шероховатости поверхности кварца $\left(\sigma^{2}\right)$ в выбранных диапазонах частот после экспозиции в плазме $\mathrm{D}_{2}$ и $\mathrm{D}_{2} / \mathrm{N}_{2}$, вычисленные из $1 D$ PSD-функций на рис. 4. В скобках указаны величины эффективной шероховатости $\sigma$, [nm]

\begin{tabular}{c|c|c|c}
\hline \multirow{2}{*}{$\begin{array}{c}\text { Интервал частот } \\
\left(f_{1}-f_{2}\right), \mu \mathrm{m}^{-1}\end{array}$} & КУ-исходные & КУ-плазма $\mathrm{D}^{2}$ & $\sigma^{2}, \mathrm{~nm}^{2}(\sigma \pm 0.05 \sigma, \mathrm{nm})$ \\
\cline { 2 - 4 } & $0.6 \pm 0.04(0.77)$ & $0.49 \pm 0.04(0.7)$ & $0.28 \pm 0.03(0.53)$ \\
\hline $0.2-1$ & $0.4 \pm 0.03(0.63)$ & $0.1 \pm 0.02(0.32)$ & $0.03 \pm 0.01(0.17)$ \\
\hline $1-3$ & $0.55 \pm 0.03(0.74)$ & $0.13 \pm 0.02(0.36)$ & $0.03 \pm 0.01(0.17)$ \\
\hline $3-25$ & $1.55 \pm 0.1(1.25)$ & $0.72 \pm 0.08(0.85)$ & $0.33 \pm 0.05(0.57)$
\end{tabular}

каждом из трех выделенных интервалов $\Delta f$ величина $\sigma^{2}$ уменьшилась (табл. 2).

В интервале низких частот $\left(0.2-1 \mu \mathrm{m}^{-1}\right)$, вносящих основной вклад в шероховатость поверхности, наклон PSD-функций выражен слабо, что связано с хаотически распределенными первичными дефектами (царапинами, выступами, отдельными углублениями). После экспозиции в плазме $\mathrm{D}_{2}$ и $\mathrm{D}_{2} / \mathrm{N}_{2}$ абсолютные значения PSDфункций понизились, а наклон увеличился, особенно после экспозиции в смеси $\mathrm{D}_{2} / \mathrm{N}_{2}$, когда толщина удаленного слоя составила $1.2 \mu \mathrm{m}$. Однако следы от первичной полировки (рис. 4, $b$ ) по-прежнему вносили основной вклад в эффективную шероховатость $\sigma^{2}$ и $\sigma$ (табл. 2).

В области средних частот $\left(1-3 \mu \mathrm{m}^{-1}\right)$ PSD-функция от исходной пластины продолжала слабо зависеть от частоты. Дефекты механического происхождения вносили основной вклад в PSD-функцию. После экспозиции в плазме $\mathrm{D}_{2}$ и $\mathrm{D}_{2} / \mathrm{N}_{2}$ темп изменения функций от частоты возрос и показатель степени во фрактальном представлении увеличился до значения $\beta=2.75 \pm 0.1$ (плазма $\mathrm{D}_{2}$ ) и $\beta=3.1 \pm 0.1$ (плазма $\mathrm{D}_{2} / \mathrm{N}_{2}$ ). По мере увеличения толщины распыленного слоя кварца вклад в шероховатость первичных полировочных царапин и выбоин сокращался. На частоте около $3 \mu \mathrm{m}^{-1}$ появился четкий перегиб. Величины $\sigma$ уменьшились в пять и десять раз.

В интервале высоких частот $\left(3-25 \mu \mathrm{m}^{-1}\right) 1 D$ PSDфункция исходной поверхности уменьшалась по степенному закону $f^{-3.7}$. Функциональная зависимость значений PSD от частоты вновь сформированных поверхностей после перегиба может быть представлена как $f^{-2}$. В указанном интервале частот эти функции оказались подобны.

Мы предположили, что функциональный вид кривых в интервале низких и средних частот исходных и экспонированных в плазме поверхностей можно представить с помощью так называемой $k$-корреляционной функции $A B C[12]$ :

$$
1 D \operatorname{PSD}(f)=A /\left[1+(B f)^{2}\right]^{C / 2},
$$

в которой $A\left[\mathrm{~nm}^{3}\right]$ - усредненное постоянное значение PSD при низких частотах, $B[\mu \mathrm{m}]-$ корреляционная ширина, $C$ - подгоночный параметр (табл. 3 ).
Таблица 3. Параметры функции АВС для исходной и облученных поверхностей кварца КУ-1

\begin{tabular}{c|c|c|c|c}
\hline КУ & $A, \mathrm{~nm}^{4}$ & $B, \mu \mathrm{m}$ & $C$ & $K, \mathrm{~nm}$ \\
\hline Исходная $\left(f=0.2-20 \mu \mathrm{m}^{-1}\right)$ & 1000 & 0.33 & 4 & \\
\hline Плазма $\mathrm{D}_{2}\left(f=0.2-3 \mu \mathrm{m}^{-1}\right)$ & 900 & 0.75 & 4.2 & 100 \\
\hline Плазма $\mathrm{D}_{2} / \mathrm{N}_{2}\left(f=0.2-2 \mu \mathrm{m}^{-1}\right)$ & 800 & 1.0 & 4.4 & 25
\end{tabular}

Для функции от исходной поверхности описание с помощью представления АВС можно продолжить и в область высоких частот. Для вновь образованных поверхностей в области высоких частот $1 D$ PSD-функции имеют фрактальный вид и могут быть представлены в виде броуновского фрактала $(\mathrm{BF}): \mathrm{PSD}=K \cdot f^{-2}$, а функции PSD-поверхностей, экспонированных в плазме, во всем интервале частот - в виде суммы $A B C+\mathrm{BF}$. Представление PSD в виде суммы с фрактальным слагаемым указывает на появление областей с неупорядоченной молекулярной шероховатостью со значениями $\sigma=0.36$ и $0.17 \mathrm{~nm}$. Области с минимальной шероховатостью можно было выделить и на отдельных участках поверхности при уменьшении площади сканирования от $10 \times 10$ до $5 \times 5$ и далее до $1 \times 1 \mu \mathrm{m}$ (рис. 6).

Указанные факты позволяют предположить, что при распылении кварца легкими ионами существенный вклад в формирование рельефа вносит процесс сглаживания рельефа, впервые отмеченный при облучении $\mathrm{SiO}_{2}$ ионами $\mathrm{H}^{+}$в [13]. Мы полагаем, что сглаживание осуществляется за счет поверхностной миграции $\mathrm{Si}-\mathrm{O}$ и $\mathrm{Si}-\mathrm{O}-\mathrm{ND}$-комплексов $[4,5]$. Диффузионное, ионноиндуцированное сглаживание может происходить, если локальная скорость массопереноса молекулярных кластеров вдоль поверхности превышает массовую скорость распыления. Такой процесс возможен при относительно небольших коэффициентах распыления и полном торможении внедряемых ионов в поверхностном слое масштаба нескольких нанометров.

Сглаживание рельефа и миграция комплексов по поверхности кварца во время плазменного воздействия может быть вызвана различной вероятностью образова- 

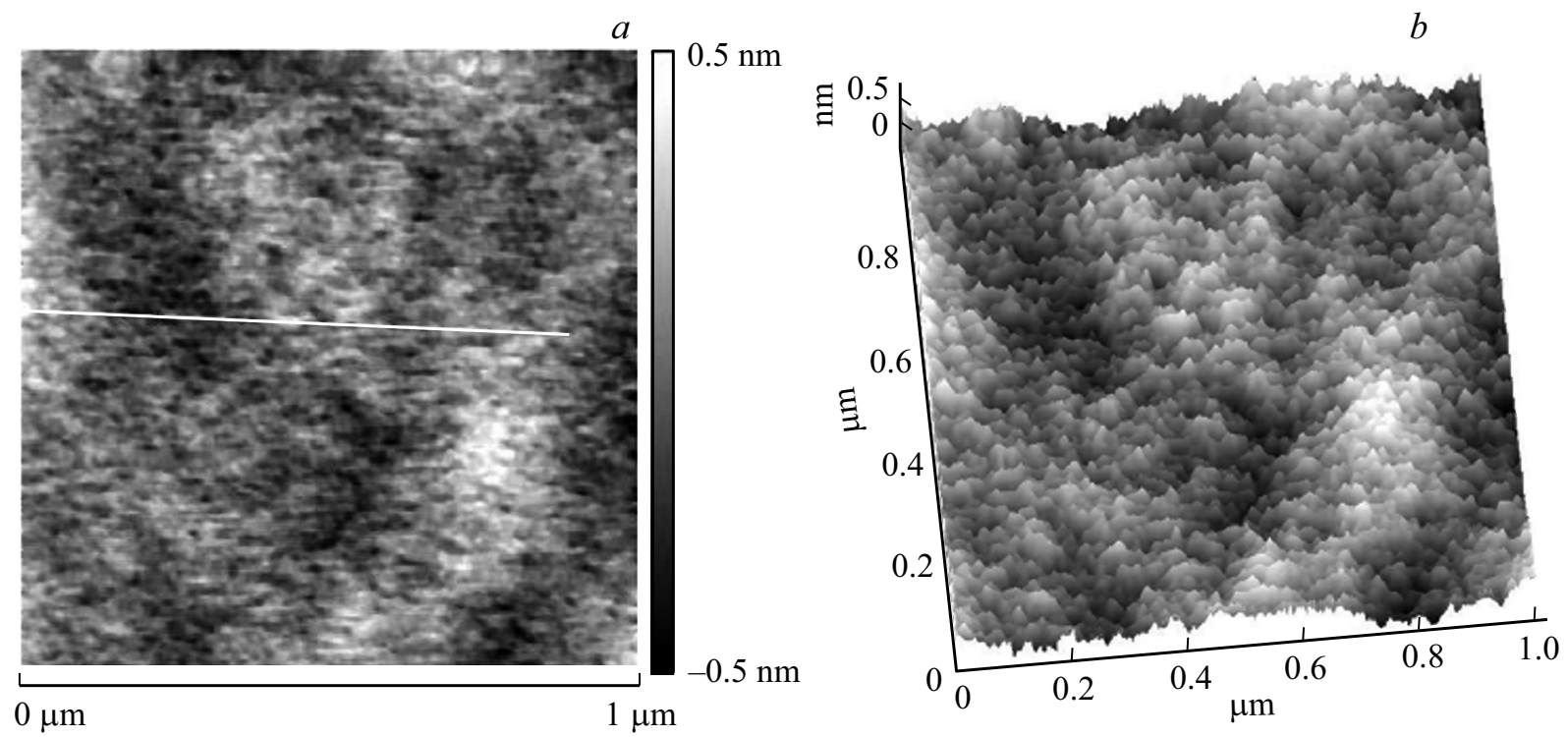

Рис. 6. Топография поверхности площадью $S_{g}=1 \times 1 \mu \mathrm{m}$ пластины КУ-1, экспонированной в ВЧ-плазме $\mathrm{D}_{2} / \mathrm{N}_{2}$ в течение $4 \mathrm{~h}(a)$; диметрическая проекция, $\left(S_{\mathrm{ph}}-S_{g}\right) / S_{g}<0.00001(b)$. Изменение высот от -0.5 до $+0.5 \mathrm{~nm} ; R_{q}=0.62 \mathrm{~nm}$.
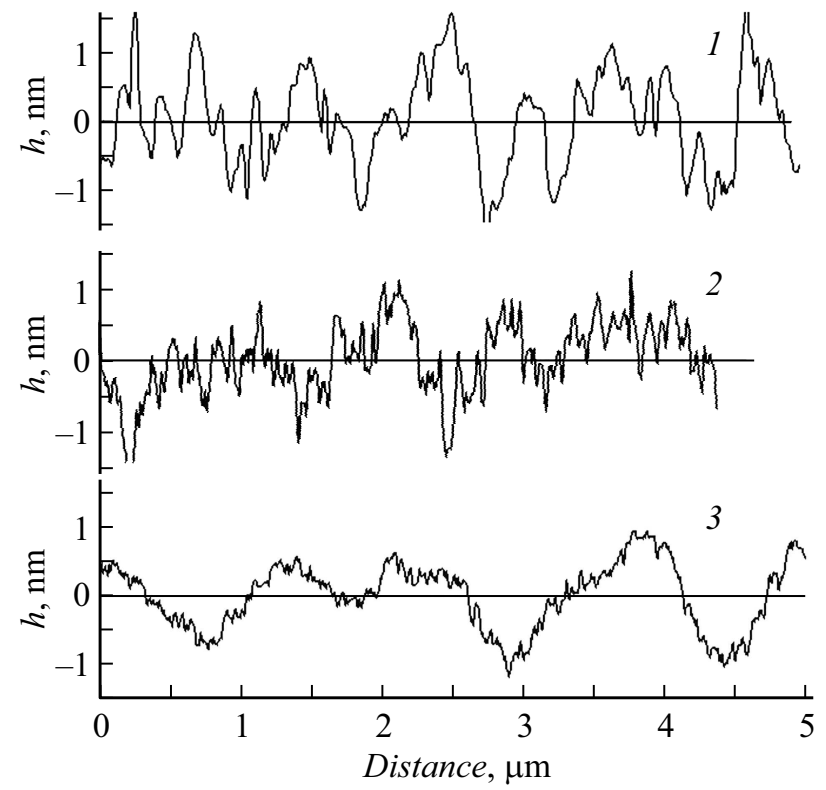

Рис. 7. Участки профилей шероховатой поверхности, полученные в АСМ: исходная поверхность (1), поверхности, экспонированные в плазме $\mathrm{D}_{2}(2)$ и смеси $\mathrm{D}_{2} / \mathrm{N}_{2}(3)$.

ния возбужденных, способных к миграции кластеров на выступах и впадинах в нанометровом диапазоне шероховатостей [14]. На вершинах выступов образуется повышенная концентрация слабо связанных с поверхностью кремниево-кислородных комплексов. Эти молекулярные $\mathrm{Si}-\mathrm{O}$-радикалы способны мигрировать по направлению к впадинам. Такое локальное перераспределение поверхностных комплексов приводит к уменьшению вклада средних и высоких частот в суммарную величину $\sigma$ (табл. 2 и рис. 4) и к сглаживанию рельефа (рис. 7). В физической химии такое явление рассматривается как капиллярный эффект. При добавлении в дейтерий азота, параллельно с увеличением коэффициента распыления, значение которого остается меньшим единицы, увеличивается число атомов отдачи, способных смещаться вдоль поверхности. Возможны различные варианты химически стимулированной радиационно ускоренной миграции.

Сглаживание рельефа можно проследить на профилях сечения поверхности, полученных в АCM (рис. 7). После плазмы $\mathrm{D}_{2}$ появляются высокочастотные компоненты шероховатости с уменьшенной амплитудой. После плазмы $\mathrm{D}_{2} / \mathrm{N}_{2}$ на профиле просматривается одна несущая частота с пространственным периодом $1.0-1.5 \mu \mathrm{m}$ (частота $0.7-1 \mu \mathrm{m}^{-1}$ ), промоделированная высокочастотными гармониками с периодами меньше $0.1 \mu \mathrm{m}$ (частоты больше $10 \mu \mathrm{m}^{-1}$ ). На формирование упорядоченных областей с молекулярной шероховатостью, возможно, указывает появление пика на PSDфункции образца кварца, экспонированного в плазме $\mathrm{D}_{2} / \mathrm{N}_{2}$ на рис. $5, a$.

\section{5. Рассеяние света шероховатой поверхностью кварца}

Детали геометрии измерения пропускания, необходимые для оценки вклада рассеяния, показаны на рис. 8 . Образец кварца 1 устанавливался на плоский участок корпуса интегрирующей сферы 2. Пучок света 3 круглого сечения диаметром $3 \mathrm{~mm}$ проходил через анализируемую кварцевую пластину, и через входное отверстие диаметром $6 \mathrm{~mm}$ поступал внутрь интегрирующей сферы. Таким образом, входная угловая апертура, определяемая как отношение радиуса входного отверстия 


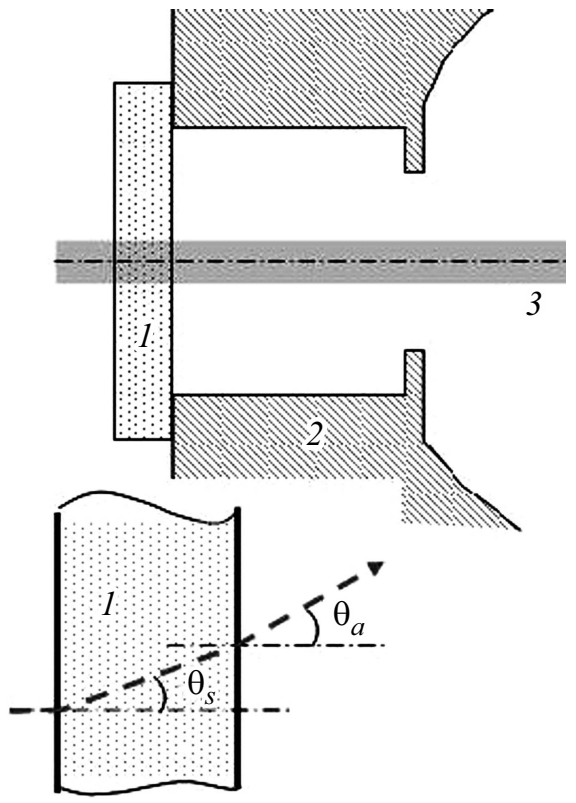

Рис. 8. Схема измерения коэффициента пропускания: 1 кварцевая пластина; 2 - входное отверстие интегрирующей сферы; 3 - пучок света. На вставке показан ход светового луча через кварцевую пластину 1 : луч падает нормально к входной поверхности пластины, рассеивается на угол $\theta_{s}$ и после преломления на выходной поверхности направляется в интегрирующую сферу под углом $\theta_{a}$.

(3 mm) к расстоянию от плоскости образца до плоскости входного отверстия интегрирующей сферы $(11 \mathrm{~mm})$, составляла $15^{\circ}$.

Распределение рассеянного света от угла рассеяния $\theta_{s}$ (Angle Resolved Scattering, ARS), определяется как отношение интенсивности света $\Delta P_{s}\left(\theta_{s}\right)$, рассеянного в телесный угол $\Delta \Omega_{s}$, к интенсивности входного потока $P_{i}$ :

$$
\operatorname{ARS}\left(\theta_{s}\right)=\Delta P_{s}\left(\theta_{s}\right) / \Delta \Omega_{s} P_{i}
$$

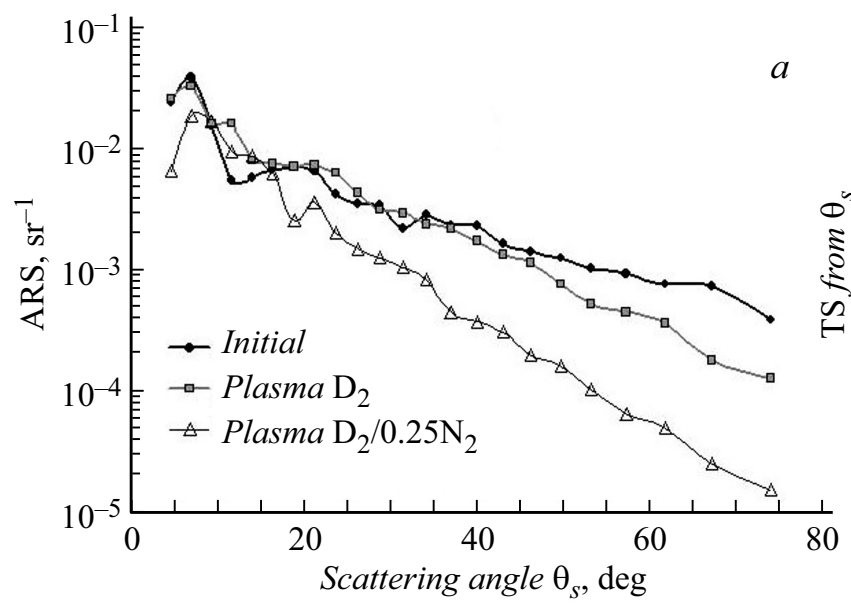

При отражении света с длиной волны $\lambda$ от поверхности и малой величине шероховатости по отношению к длине волны света $(\sigma / \lambda<0.02) A R S$ описывается формулой Рэлея-Райса (см., например, [15]):

$$
A R S\left(\theta_{s}\right)=\left[4 \pi \cos \theta_{s}\right]^{2} \cos \theta_{i} \operatorname{PSD}(f) R / \lambda^{4},
$$

где $\theta_{i}$ - угол падения света на пластину кварца, $\theta_{s}-$ угол рассеяния, $\operatorname{PSD}(f)$ - двумерная спектральная плотность мощности (рис. 5,b), а $R$ - коэффициент зеркального отражения.

Подчеркнем, что рассеяние света прямо пропорционально значениям 2D PSD-функции.

Угол рассеяния и пространственная частота $\mathrm{f}$ связаны дифракционным уравнением

$$
f=\left|\sin \theta_{s}-\sin \theta_{i}\right| / \lambda .
$$

В работе [16] показано, что в задаче по прохождению света через границу воздух (или вакуум)/прозрачная среда (рис. 1) с показателем преломления $n$, вместо числа 4 в формуле (2) следует использовать $2(n-1)$, а вместо коэффициента отражения $R-$ коэффициент пропускания $T=1-R$.

Результат расчета ARS по формуле (2) для нормального падения света на поверхность кварца $(n=$ $\left.=1.46, \theta_{i}=0\right)$ представлен на рис. 9, $a$. Расчеты выполнены с использованием данных PSD, приведенных на рис. 5, $b$. Коэффициент пропускания границы воздух-кварц был принят равным 97\%. Поскольку ARS быстро убывает с увеличением длины волны, оценки вклада рассеяния выполнены для наименьшей длины волны в наших измерениях по прохождению света сквозь пластину $(\lambda=400 \mathrm{~nm}$, рис. 3$)$. При этом нижняя граница пространственных частот обусловлена площадью сканирования в АCM, а верхняя граница - величиной $1 / \lambda=2.5 \mu \mathrm{m}^{-1}$, так как значения PSD-функций на больших частотах не дают вклада в рассеяние по условию (3).

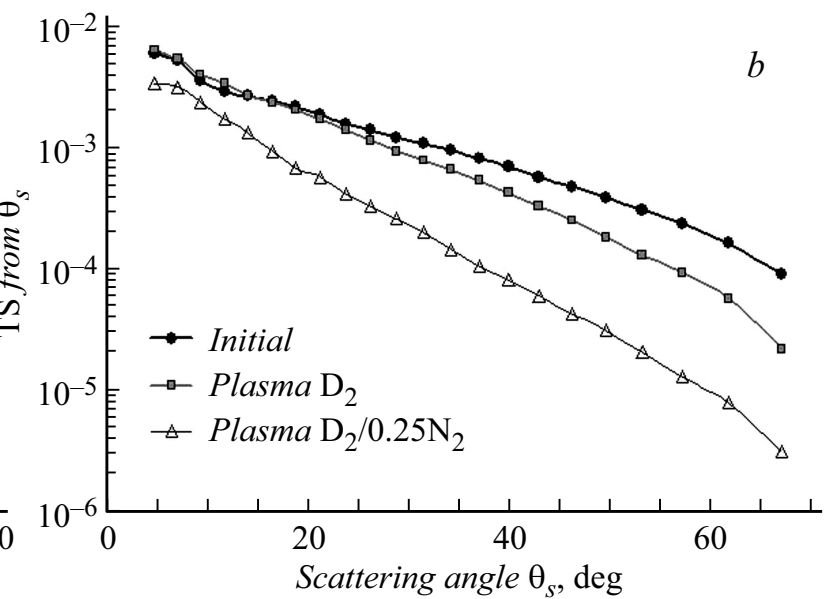

Рис. 9. Рассеяние света при прохождении через границу воздух-кварц: угловое распределение рассеянного света (ARS) (a) и интегральный поток рассеяния (TS) в углы от $\theta_{s}$ до $90^{\circ}(b)$. 
Принимая, что выходная сторона образца кварца идеальна (шероховатость равна нулю) и рассеяние также равно нулю, можно оценить, что в сферу попадает свет, выходящий из образца под углом $\theta_{a}$, который связан с углом рассеяния $\theta_{s}$ (см. вставку на рис. 8) законом преломления Снеллиуса

$$
\left(\sin \theta_{s}\right) \cdot n=\sin \theta_{a} .
$$

Для кварца $n=1.46$, и в приближении малого диаметра светового пучка, когда $\theta_{a}$ близок к угловой апертуре $15^{\circ}$, имеем, что в сферу попадает свет, рассеянный на входной поверхности на углы менее $\theta_{s}=10^{\circ}$.

Зависимость интегрального потока рассеяния (Total Scattering, TS) на углы от $\theta_{s}$ до $90^{\circ}$ были вычислены с помощью интегрирования в интервале указанных углов с использованием полученных значений ARS [15]:

$$
T S\left(\theta_{a}\right)=2 \pi \int A R S\left(\theta_{s}\right) \sin \theta_{s} d \theta_{s} .
$$

Вместо интегрирования величина $T S$ определялась площадью под кривой зависимостей $A R S$ от угла в радианах на рис. 9, $a$. Результат представлен на рис. 9, $b$.

Из данных на рис. 9, $b$ следует, что при использованной геометрии измерения пропускания с апертурой $\theta_{a}=15 o$ вклад рассеяния для исходных и обработанных плазмой образцов не превышал $0.5 \%$ (см. величину TS при $10^{\circ}$ на рис. $\left.8, b\right)$ и не мог быть зафиксирован использованной методикой измерения пропускания (см. фоновый шум на рис. 3).

\section{Заключение}

По результатам измерения скоростей травления кварца, анализов СП, РФЭС, АСМ можно утверждать, что экспозиция кварцевого окна в ВЧ-плазме $\mathrm{D}_{2}$ и $\mathrm{D}_{2} / \mathrm{N}_{2}$ сопровождалась распылением поверхности кварца со скоростью 60 и $300 \mathrm{~nm} / \mathrm{h}$ с уменьшением шероховатости $R_{q}$ до значений 0.85 и $0.57 \mathrm{~nm}$ соответственно. Светопропускание кварца оставалось неизменным в интервале длин волн 400-1000 nm с точностью $0.5 \%$.

Показано, что с помощью анализа АCM изображений и соответствующих им PSD-функций можно получить дополнительную информацию о вкладе различных пространственных частот в формирование топологической картины поверхности, процессах сглаживания рельефа и процессах диффузного рассеяния света.

Травление в низкотемпературной плазме ВЧ-разряда с использованием дейтерия или смеси D2/N2 является приемлемой методикой чистки кварца при температурах $20-100^{\circ} \mathrm{C}$ от загрязнений продуктами эрозии первой стенки в токамаке. Результаты экспериментов по очистке кварца от металлических осадков, моделирующих загрязнения в ИТЭР, планируется представить в отдельной публикации.

\section{Конфликт интересов}

Авторы заявляют, что у них нет конфликта интересов.

\section{Список литературы}

[1] D.V. Orlinski, V.T. Gritsyna. Problems of Atomic Science and Technology, 3, Series: Plasma Physics (5), 60 (2000).

[2] S. Takamura, T. Aota, Y. Uesugi, Y. Kikuchi, S. Maenaka, K. Fujita. Nucl. Fusion, 59, 046015 (2019).

[3] V.L. Bukhovets, A.E. Gorodetsky, R.Kh. Zalavutdinov, A.V. Markin, L.P. Kazansky, I.A. Arkhipushkin, A.P. Zakharov, A.M. Dmitriev, A.G. Razdobarin, E.E. Mukhin. Nucl. Mater. Energy, 12, 458 (2017).

[4] M. Zhou, M. Chen. Chem. Phys. Lett., 349 (1), 64 (2001).

[5] W. Orellana. Appl. Phys. Lett., 84 (6), 933 (2004).

[6] H.F. Winters, J.W. Coburn. Surf. Sci. Reports, 14, 161 (1992).

[7] A. Gujrati, S.R. Khanal, L. Pastewka, T.D.B. Jacobs. ACS Appl. Mater. Interfaces, 10, 29169 (2018). DOI: $10.1021 /$ acsami.8b09899

[8] B.W. Scheer, J.C. Stover. SPIE, 3141, 78 (1997).

[9] N.I. Chkhalo, S.A. Churin, A.E. Pestov, N.N. Salashchenko, Yu.A. Vainer, M.V. Zorina. Optics Express, 22 (17), 20094 (2014). DOI:10.1364/OE.22.020094

[10] Ю.А. Вайнер, М.В. Зорина, А.Е. Пестов, Н.Н. Салащенко, Н.И. Чхало, В. Ермаков, С.И. Канорский, С.В. Кузин, С.В. Шестов, И.Л. Струля. Поверхность. Рентген., синхротр. и нейтрон. исслед., 8, 5 (2015).

[11] T. Jacobs, T. Junge, L. Pastewka. Surf. Topography: Metrology and Properties, 5 (1), 013001 (2017). DOI: $10.1088 / 2051-672 X / a a 51 f 8$

[12] J.E. Harvey, S. Schroder, N. Choi, A. Duparre. Optical Engineer., 51 (1), 013402 (2012),

[13] E. Chason, T.M. Mayer. Appl. Phys. Lett., 62 (4), 363 (1993).

[14] K. Bhattacharjee, S. Bera, D.K. Goswami, B.N. Dev. Nucl. Instrum. Methods in Phys. Res. B, 230, 524 (2005).

[15] S. Schroder, T. Herffurth, A. Duparre, J.E. Harvey. Proceeding of SPIE - The Intern. Society for Optical Engineer., 8169-28, 4, 1 (2011). DOI: 10.1117/12.896989

[16] R. Rougeot, R. Flamary, D. Mary, C. Aime. Astronomy \& Astrophysics, 626A1, 1 (2019).

https: // doi.og/ 10.1051/0004-6361/201834634 